\title{
Characterization of AZ31-NbC surface composite fabricated by friction stir processing
}

\author{
Muralimanokar M. ${ }^{1}$, Vaira Vignesh $R .{ }^{1}$, Padmanaban $R .{ }^{1}$, Suganya Priyadharshini $G .{ }^{2}$ \\ ${ }^{1}$ Department of Mechanical Engineering, Amrita School of Engineering, Coimbatore, \\ Amrita Vishwa Vidyapeetham, India \\ ${ }^{2}$ Department of Mechanical Engineering, Coimbatore Institute of Technology, Coimbatore, \\ Anna University, India \\ E-mail: r.vairavignesh@gmail.com
}

AZ31D magnesium alloy is widely used in automotive, aircraft, and aerospace applications because of its high strength to weight ratio. However, the softness of the alloy results in higher wear rate and the high activity results in higher corrosion rate. With an aim of reducing the wear rate and corrosion rate of AZ31 alloy, surface composite of AZ31 alloy is fabricated by reinforcing niobium carbide $(\mathrm{NbC})$ by friction stir processing. The microstructure and dispersion of the reinforcements in AZ31-NbC surface composite is analysed by optical microscopy. In addition, the microhardness and tribological characteristics of the developed AZ31-NbC surface composite are investigated. The results demonstrated an increase in microhardness $(23.2 \%)$ and the decrease in wear rate $(15.6 \%$ for a normal load of $2 \mathrm{~kg}$ ) in the developed AZ31-NbC surface composite with respect to the base material. The immersion corrosion test was performed to analyse the corrosion rate of the developed AZ31-NbC surface composite in simulated sea water environment ( $3.5 \mathrm{wt} \% \mathrm{NaCl}$ solution). The results indicate that the corrosion rate of the developed AZ31-NbC surface composite is higher than that of base material. A comprehensive analysis on the wear and corrosion mechanism of the developed AZ31-NbC surface composite is presented.

\section{INTRODUCTION}

Magnesium alloys known for the light weightiness is broadly used in numerous engineering applications interfacial [1-3]. Magnesium is alloyed with aluminium, zinc, silicon, copper and rare earth metals to enable definite applications in automobile, aerospace, and optical components [2,4]. Although magnesium alloys are used in structural applications, their poor corrosion and wear resistance limits their utility. This necessitated an expansion and manufacture of magnesium alloys with better strength and improved corrosion and wear property $[5,6]$. One of the widely accepted technologies to obtain desired properties in the magnesium alloy is through fabrication of composites [7, 8].

Composites are materials that are fabricated by reinforcing one new phase in the base matrix. Composites are advantageous over conventional alloy systems, as the former possesses desired and better properties $[9,10]$. Surface composites are suitable materials for engineering applications involving surface interactions. Surface composites results in augmented characteristics of composites on the surface while retaining properties of the base material.

Standard methods for formulating surface composites consist of liquid phase processing and at higher temperatures such as plasma spraying and laser melting. The high temperature favors reaction between metal matrix and the reinforcement. In addition, liquid-state processing lead to progressively degraded properties. Hence, solid-state processing of composites is beneficial. Friction stir processing is emerging as a promising technique for making surface composites [11, 12]. Mishra et al., reviewed the fabrication of surface composites by FSP [13-15]. The common reinforcements that are used to fabricate composites by FSP include CNT [16], MWCNT [17, 18], $\mathrm{SiC}[19,20], \mathrm{SiO}_{2}[21,22], \mathrm{ZrO}_{2}$ [21], HAP [23], $\mathrm{Al}_{2} \mathrm{O}_{3}[24,25]$, fly ash [26], TiC [27, 28] and $\mathrm{WC}[13,29]$.

In this work, surface composite of AZ31 alloy is fabricated by reinforcing $\mathrm{NbC}$ using FSP. The study presents the evolution of microstructure, microhardness, corrosion rate and wear rate of the developed surface composite.

\section{MATERIALS AND METHODS}

\section{Material}

The base material used in the study was wrought magnesium alloy AZ31. The composition of the alloy is given in Table 1. The wrought plate was cut in to workpieces of dimensions of $150 \times 50 \times 4 \mathrm{~mm}$. A square groove of dimension $1 \times 1 \times 100 \mathrm{~mm}$ was machined on the workpiece to fill the reinforcements. Niobium Carbide (NbC) particles of $\sim 30 \mu \mathrm{m}$ was used as reinforcement. 
Tab. 1. Composition of AZ31 alloy

\begin{tabular}{|c|c|c|c|c|c|c|c|}
\hline $\mathbf{M g}$ & $\mathbf{A l}$ & $\mathbf{F e}$ & $\mathbf{M n}$ & $\mathbf{N i}$ & $\mathbf{S i}$ & $\mathbf{Z n}$ & $\mathbf{C u}$ \\
\hline Bal. & 3.3 & 0.007 & 0.25 & 0.0005 & 0.6 & 1.1 & 0.01 \\
\hline
\end{tabular}

\section{Friction stir processing}

The workpieces were cleaned with acetone before FSP trial. The reinforcements were filled in the groove and a sealing pass was performed using the sealing tool. Then FSP trials were performed on the specimens. A dwell time of 60 minutes was provided between the consecutive FSP passes. The optimum process parameters were obtained from previous research work (tool rotation speed of $1200 \mathrm{rpm}$ and tool traverse speed of $45 \mathrm{~mm} / \mathrm{min}$ using a sealing tool of shoulder diameter $18 \mathrm{~mm}$ and FSP tool of shoulder diameter of $18 \mathrm{~mm}$; pin diameter of $5 \mathrm{~mm}$ and pin height of $3.5 \mathrm{~mm}$ ).

\section{Microstructure analysis}

Specimen of dimension $10 \times 10 \mathrm{~mm}$ were cut and were mounted using cold setting compound. Acetic picral was used as an etchant. The specimens were polished to obtain mirror finish. The etched surface was observed in an optical microscope at various magnifications.

\section{Vickers microhardness}

For micro hardness testing, the specimens were prepared as described in the microstructure analysis. The polished specimens were indented at a normal load of $100 \mathrm{gf}$ for 15 seconds. The average of five microhardness measurements that were taken at different points in the stir zone of the developed surface composite is reported.

\section{Wear test}

The specimens of dimension $50 \times 20 \mathrm{~mm}$ were cut and were mounted in a steel tube to make the pin. The specimens were slid against EN31 steel disc at normal condition (temperature of $25^{\circ} \mathrm{C}$; dry condition). The test parameters were as follows: sliding velocity of $0.6 \mathrm{~m} \mathrm{~s}^{-1}$, sliding distance of $597.6 \mathrm{~m}$ ). The load was varied between $1 \mathrm{~kg}, 1.5 \mathrm{~kg}$ and $2 \mathrm{~kg}$. The wear rate was calculated using the equation (1).

$$
\text { Wear rate }=\frac{\Delta M}{F \cdot D}
$$

where $\Delta M$ is Mass loss, $F$ is normal load and $D$ is sliding distance. The codes and details of the specimens is given in Table 2.

\section{Immersion corrosion test}

The corrosion test was performed for the developed surface composite specimen along with the base material. The specimens were into required dimension of $10 \times 10 \mathrm{~mm}$ and mirror-polished on all sides. The simulated sea water solution $(3.5 \% \mathrm{NaCl}$ solution) was prepared by mixing $35 \mathrm{~g}$ of $\mathrm{NaCl}$ in $1000 \mathrm{ml}$ of distilled water. Eighteen specimens (nine from base material and nine from the developed surface composite) were placed in individual conical flask that was filled with $250 \mathrm{ml}$ of simulated sea water. The conical flasks were placed in a thermostatic bath and maintained at $40^{\circ} \mathrm{C}$. The samples were cleaned in ultrasonicator filled with acetone. Three specimens were taken out from the conical flask (both from base material and developed surface composite) at an interval period of $24 \mathrm{hrs}, 48 \mathrm{hrs}$, and $96 \mathrm{hrs}$. The mass loss was found out using a precision weight balance of readability $0.0001 \mathrm{~g}$. The corrosion rate of the specimen was calculated using the equation (2).

$$
\text { Corrosion rate }=\frac{K \cdot \Delta M}{A \cdot T \cdot D}
$$

where $K=8.76 \times 10^{4}, \Delta M$ is mass loss, $A$ is surface area, $T$ is time, $D$ is density of magnesium alloy. The codes of the specimens are given in Table 3.

Tab. 2. Wear test details

\begin{tabular}{|l|c|c|c|c|}
\hline \multirow{2}{*}{ Details } & \multirow{2}{*}{ Code } & \multicolumn{3}{|c|}{ Wear test parameters } \\
\cline { 3 - 5 } & & Load (kg) & Sliding velocity (m/s) & Sliding distance (m) \\
\hline \multirow{3}{*}{ Average wear rate of base material } & B01 & 1.0 & 0.6 & 597.6 \\
\cline { 2 - 5 } & B02 & 1.5 & 0.6 & 597.6 \\
\cline { 2 - 5 } & B03 & 2.0 & 0.6 & 597.6 \\
\hline \multirow{2}{*}{$\begin{array}{l}\text { Average wear rate of developed } \\
\text { surface composite }\end{array}$} & F01 & 1.0 & 0.6 & 597.6 \\
\cline { 2 - 5 } & F02 & 1.5 & 0.6 & 597.6 \\
\cline { 2 - 5 } & F03 & 2.0 & 0.6 & 597.6 \\
\hline
\end{tabular}


Tab. 3. Immersion corrosion details

\begin{tabular}{|l|c|c|}
\hline \multirow{2}{*}{ Details } & Code & $\begin{array}{c}\text { Immersion time } \\
\text { (hours) }\end{array}$ \\
\hline \multirow{2}{*}{$\begin{array}{l}\text { Average corrosion rate } \\
\text { of base material }\end{array}$} & B24 & 24 \\
\cline { 2 - 3 } & B48 & 48 \\
\cline { 2 - 3 } & B96 & 96 \\
\hline \multirow{2}{*}{$\begin{array}{l}\text { Average corrosion rate } \\
\text { of developed surface } \\
\text { composite }\end{array}$} & F24 & 24 \\
\cline { 2 - 3 } & F48 & 48 \\
\cline { 2 - 3 } & F96 & 96 \\
\hline
\end{tabular}

\section{RESULTS AND DISCUSSION}

\section{Microstructure}

Figure 1a shows the un-etched microstructure of developed surface composite that shows the $\mathrm{NbC}$ reinforcement embedded in the matrix. The Figure $1 \mathrm{~b}$ (etched) shows the dispersed $\beta$ - $\mathrm{Mg}_{17} \mathrm{Al}_{12}$ ( $\beta$-phase), and fine grains in the developed surface composite. The dark patches show the fine distribution of $\mathrm{NbC}$. No characteristic agglomeration of $\mathrm{NbC}$ was observed in the developed surface composite.

\section{Microhardness}

The microhardness of base material was observed to be $56 \mathrm{Hv}$. The microhardness value of the developed surface composite specimen was found out to be $69 \mathrm{Hv}$, which indicated $23.2 \%$ increase in hardness in the developed surface composite. The dispersion of $\beta$ phase and $\mathrm{NbC}$ with grain refinement increased the hardness

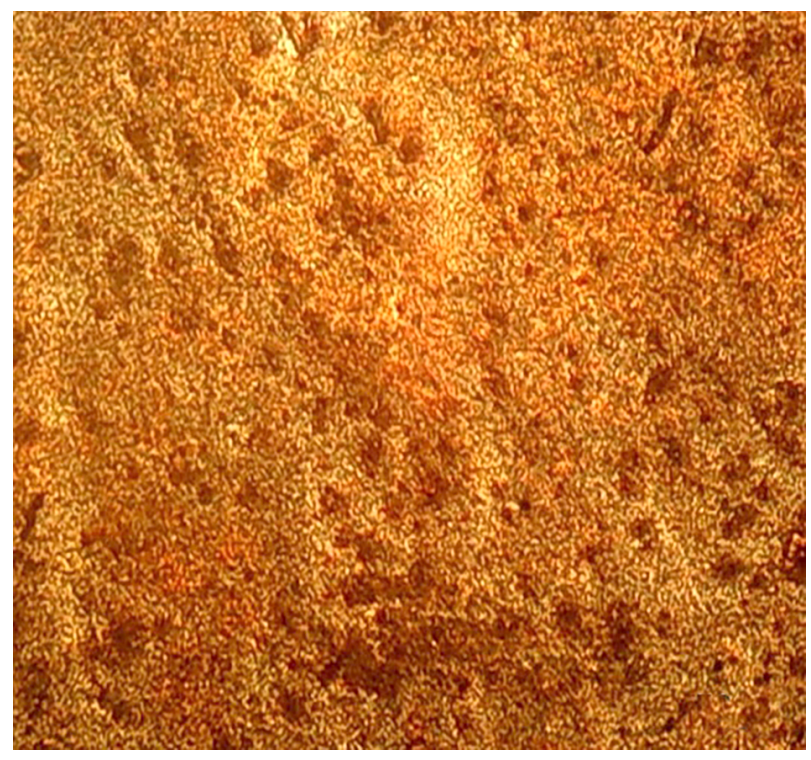

a) of the developed surface composite. The hardness of the nugget zone was found to be higher than that of the base material and thermo-mechanically affected zone.

\section{Wear rate}

Figure 2 shows the wear rate of the base material and developed surface composite at various load conditions. The wear rate of the specimen B01 was $5.339 \times 10^{-7} \mathrm{~g} / \mathrm{Nm}$ at a normal load of $1 \mathrm{~kg}$. The specimen B02 which was tested at the load of $1.5 \mathrm{~kg}$ had the wear rate of $1.2736 \times 10^{-7} \mathrm{~g} / \mathrm{Nm}, \mathrm{B} 03$ had established wear rate of $1.3987 \times 10^{-7} \mathrm{~g} / \mathrm{Nm}$ at $2 \mathrm{~kg}$ of load.

The wear rate for the developed surface composite are lower than that of the base material at all the loads. F01 had the wear rate $1.1281 \times 10^{-7} \mathrm{~g} / \mathrm{Nm}$ with the normal load of $1 \mathrm{~kg}, \mathrm{~F} 02$ has the wear rate $1.2192 \times 10^{-7} \mathrm{~g} / \mathrm{Nm}$

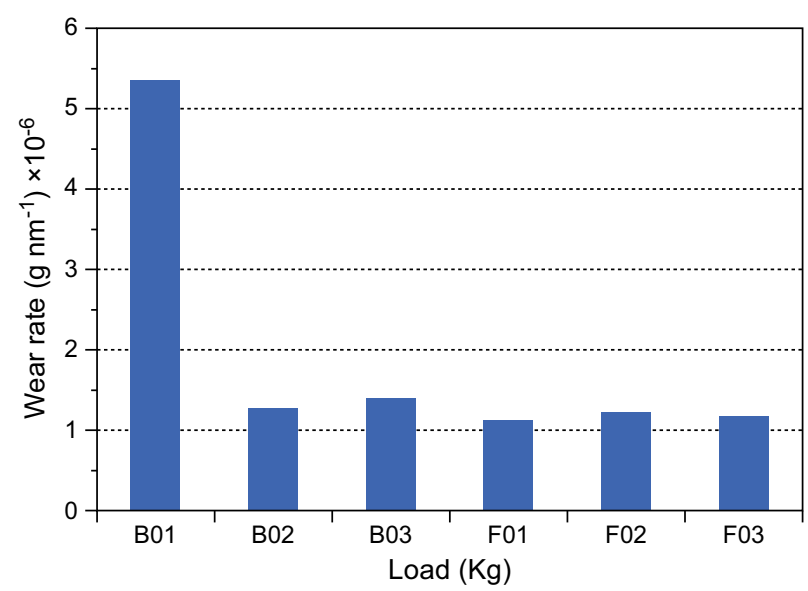

Fig. 2. Wear rate of the base material and developed surface composite at various loads

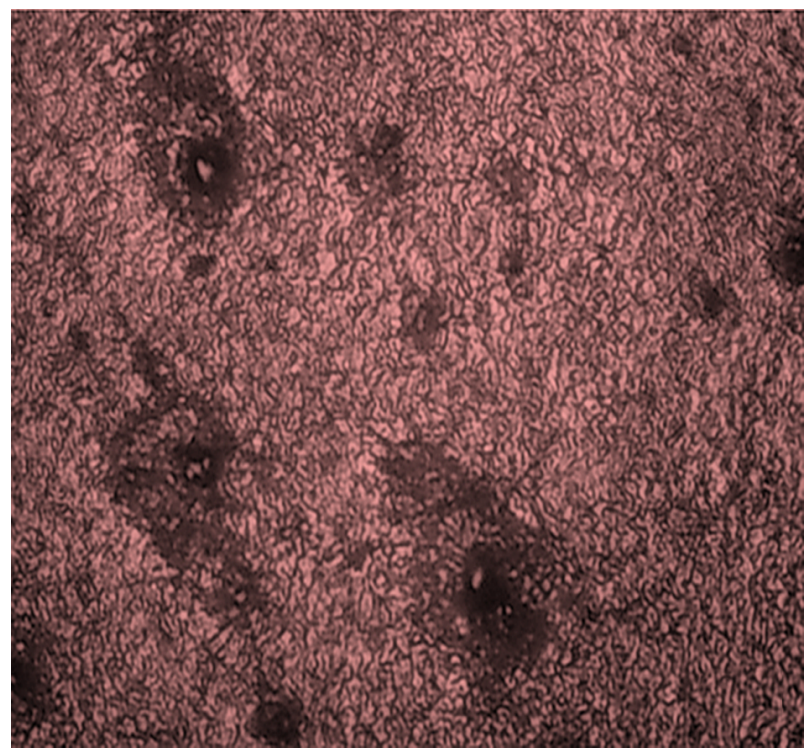

b)

Fig. 1. AZ31-NbC surface composite: a) un-etched; b) etched 
with the normal load of $1.5 \mathrm{~kg}$ and F03 has the wear rate $1.1794 \times 10^{-7} \mathrm{~g} / \mathrm{Nm}$ with normal load of $2 \mathrm{~kg}$. The percentage decrease in wear rate of $\mathrm{F} 01$ is $78.8 \%, \mathrm{~F} 02$ is $4.2 \%$ and $\mathrm{F} 03$ is $15.6 \%$ than that of the corresponding base material B01, B02, and B03. The details on the mode of wear is discussed in the following section

\section{Surface morphology}

Figure 3 indicates the worn surface morphology of the specimen B03 that was worn at a load of $2 \mathrm{~kg}$. Formation of wear debris in a clustered manner and minor cracks were observed, as shown in in Figure 3 a. Deep grooves and cracks on the worn surface, as shown in Figure 3b, were created by the concentration of load in a localized spot. Figure $3 \mathrm{c}$ displays the furrows, mild cracks and scratches. Removal of material as a cut pieces lead to delamination, as shown in Figure 3d. Besides, ploughing phenomenon, which is caused by the dragging of debris in the course of the wear, was prevalent on the worn surface of the specimen. The results indicated a combined adhesive and abrasive wear phenomenon in the specimen B03. Figure 4 shows the worn surface morphology of the specimen F03 that was worn at a load of $2 \mathrm{~kg}$. Figure $4 \mathrm{a}$ shows the spalling on the worn surface that was chanced by the ejection of material in the form of small particles. Figure $4 \mathrm{~b}$ picturizes the wear debris and Figure $4 \mathrm{c}$ shows the localized forms of wear (furrows and scratches). Shallow grooves and wear debris were observed in the Figure 4d. The specimen F03 exhibited comparatively lesser abrasive features than that of the specimen B03 that was slid at same load. Figure 5 shows the surface morphology of the worn specimen F01 that was worn at a load of $1 \mathrm{~kg}$. Figure $5 \mathrm{a}$ shows pits and mild scratches. Some traces of wear debris are observed in Figure 5b. Material removal in the form of small piece of coatings and chips can be seen in the Figure $5 \mathrm{c}$. Figure $5 \mathrm{~d}$ clearly shows the wear debris, scratches. The wear mechanism of the developed surface compoiste was in the region of mild wear at low load and in the region of transition zone (adhesive wear and abrasive wear) at high loads.

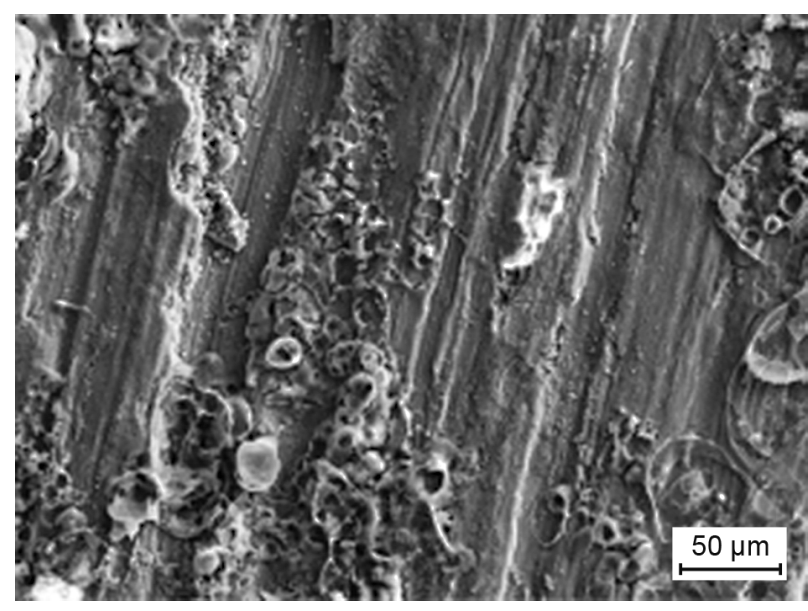

a)

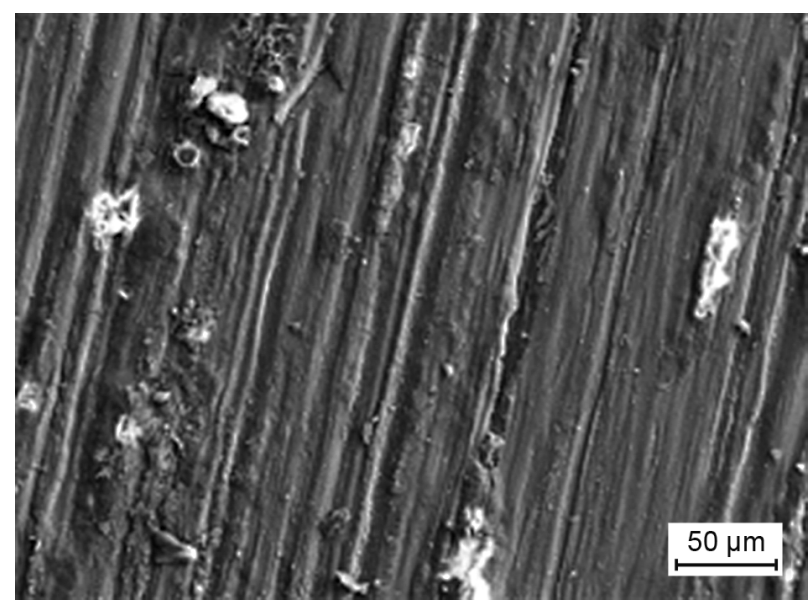

c)

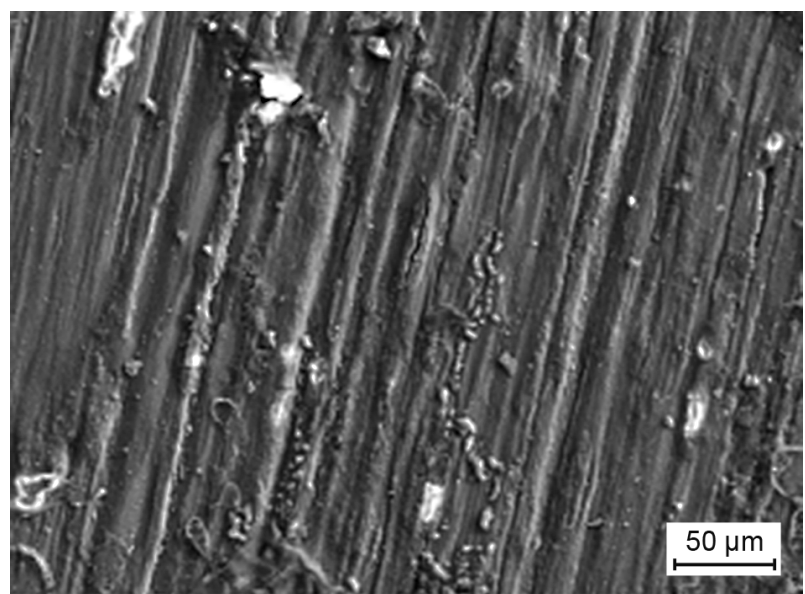

b)

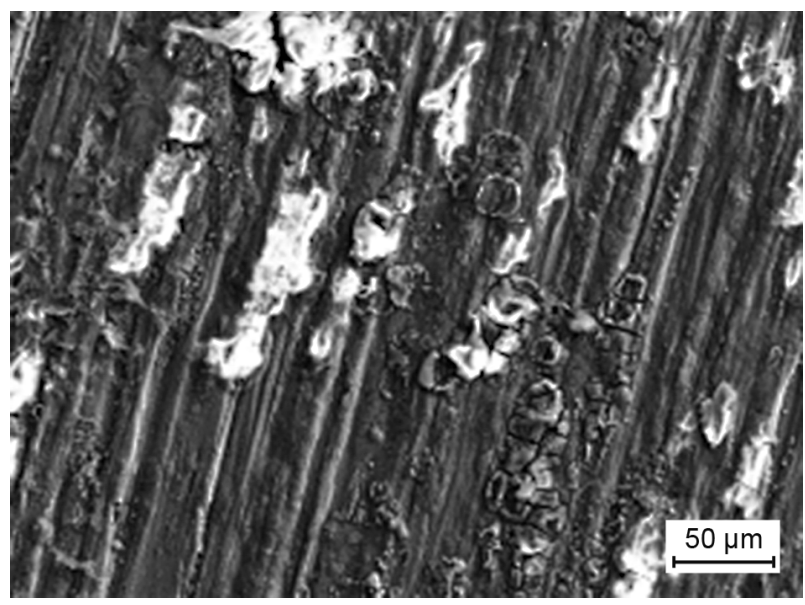

d)

Fig. 3. Surface morphology of B03 specimen 
Characterization of AZ31-NbC surface composite fabricated... Muralimanokar M., Vaira Vignesh R., Padmanaban R. et al.

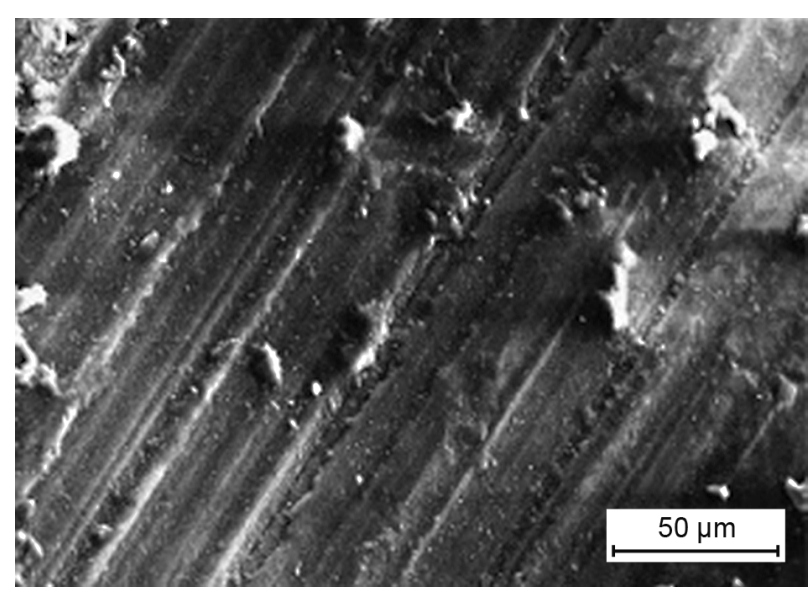

a)

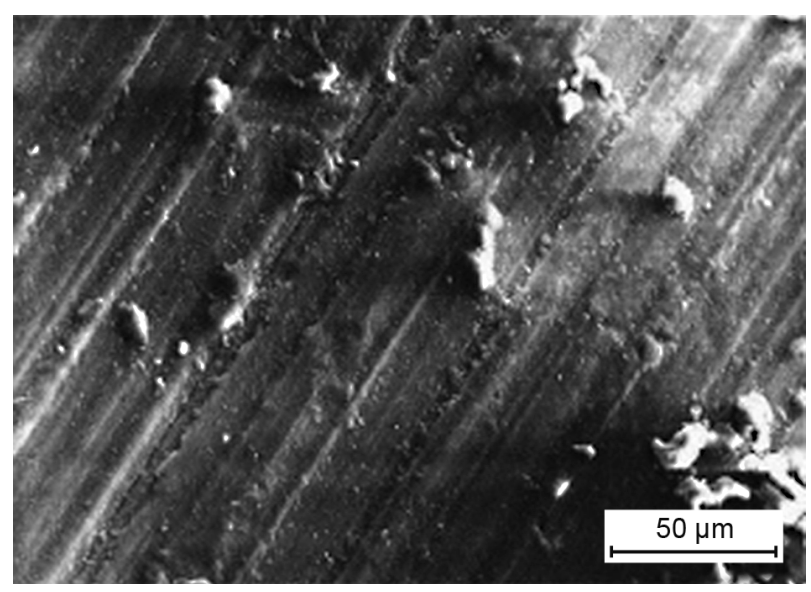

c)

Fig. 4. Surface morphology of F03 specimen

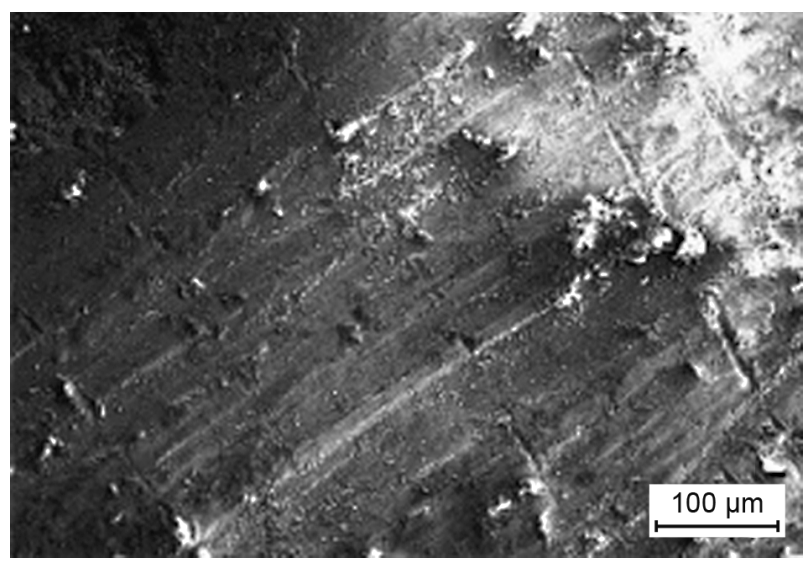

a)

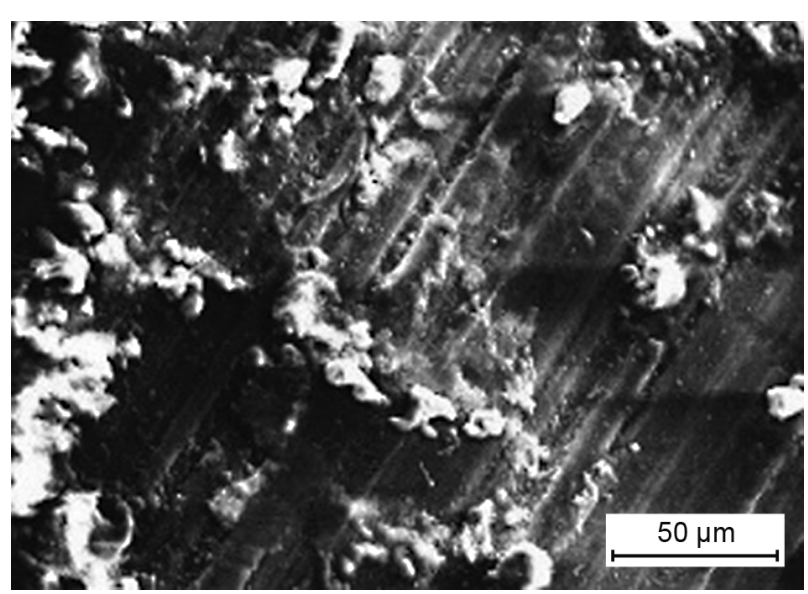

b)

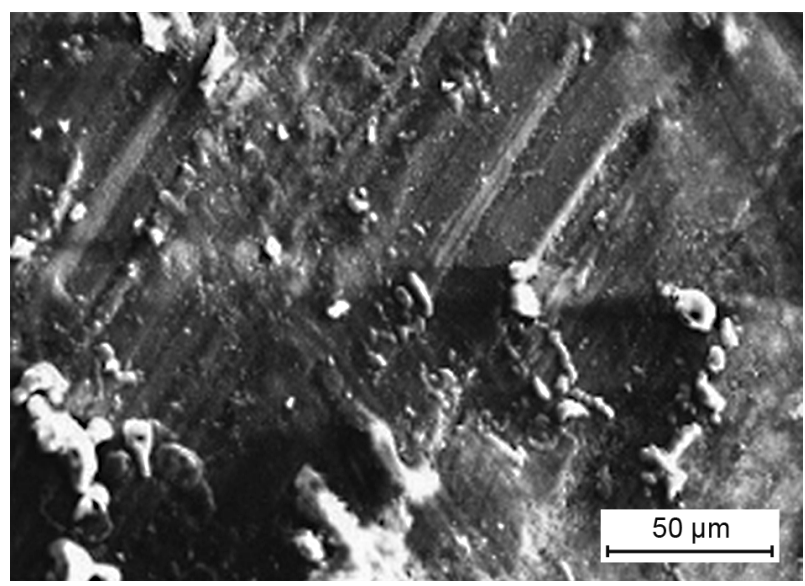

d)

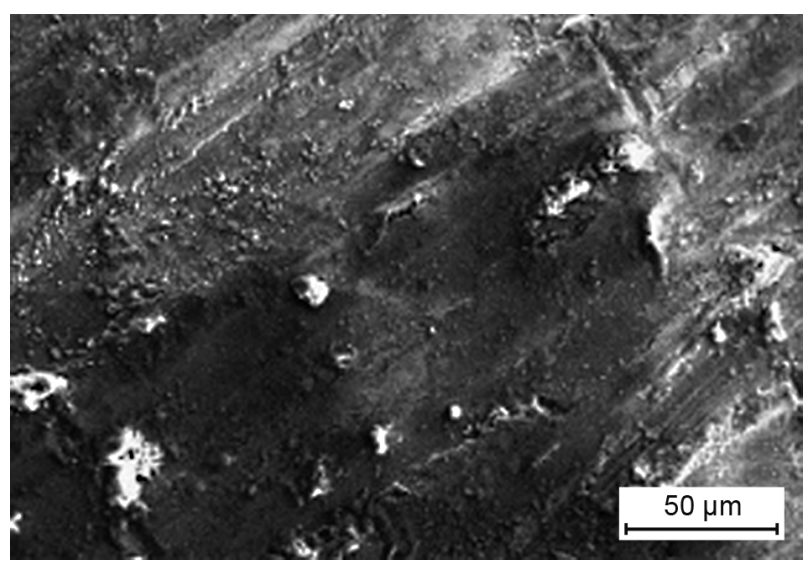

b)

Fig. 5. Surface morphology of F01 specimen (continue on next page) 


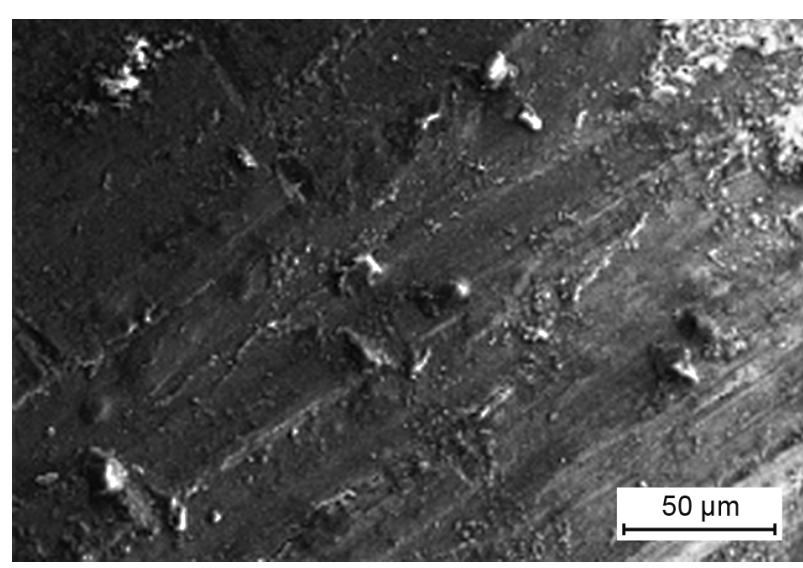

c)

Fig. 5. Surface morphology of F01 specimen

\section{Elemental composition analysis}

Figure 6 shows the elemental composition of the specimen B03 that had the highest wear rate. The elements on the surface were $\mathrm{Al}, \mathrm{Mg}, \mathrm{Zn}, \mathrm{O}$. The count of $\mathrm{Mg}$ is high with the atomic concentration of $67.88 \%$ and the oxygen content of $56.55 \%$. More count of $\mathrm{O}$ indicates the oxidation of the worn surface. Figure 7 displays the elemental composition of the worn region in F03 that was worn at a normal load of $2 \mathrm{~kg}$. Occurrence of $\mathrm{Al}$, $\mathrm{Mg}, \mathrm{O}$, with trace amount of $\mathrm{Na}$ is confirmed through the analysis. The atomic concentration of $\mathrm{O}(27.89 \%)$ is higher next to $\mathrm{Mg}(69.90 \%)$, indicating the predominant oxidation of the surface in the course of wear process. Figure 8 shows the elemental analysis of the worn out region in the specimen F01 with significant counts for $\mathrm{Al}, \mathrm{Mg}, \mathrm{Zn}$, and $\mathrm{O}$. The availability of $\mathrm{Mg}$ is high in this case with the atomic concentration of $65.55 \%$ and the oxygen remains the next to $\mathrm{Mg}$ with an average atomic concentration of $33.45 \%$. This again indicates

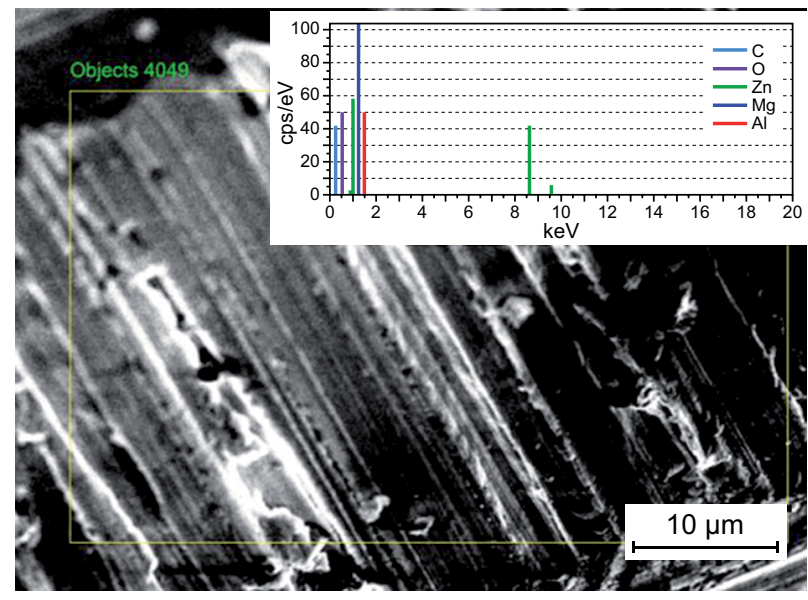

Fig. 6. Elemental composition of B03 specimen

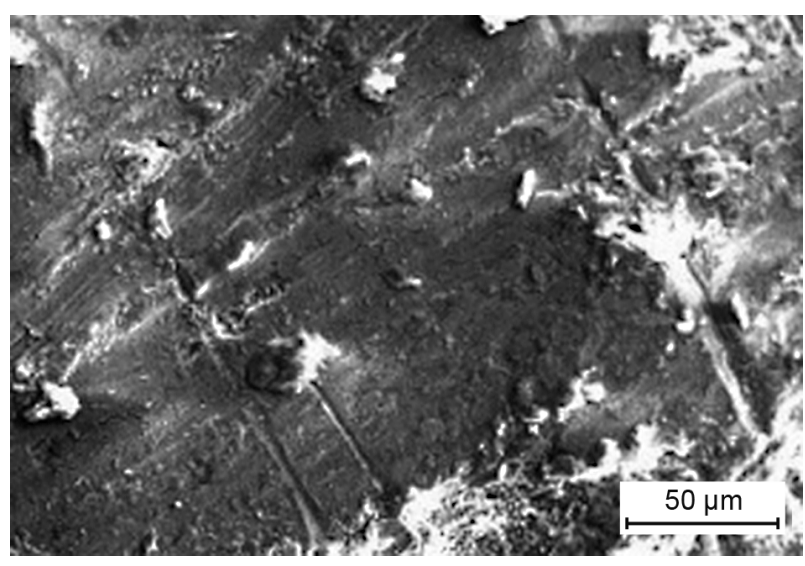

d)

the oxidation of the specimen during the course of wear. The elemental composition analysis reveals that the base material and developed surface composite undergo oxidation during the wear process.

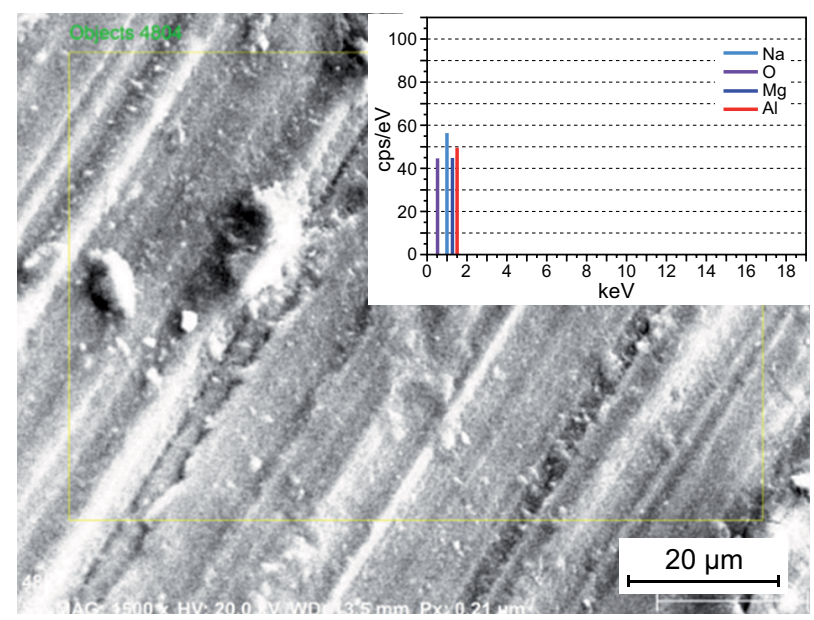

Fig. 7. Elemental composition of F03 specimen

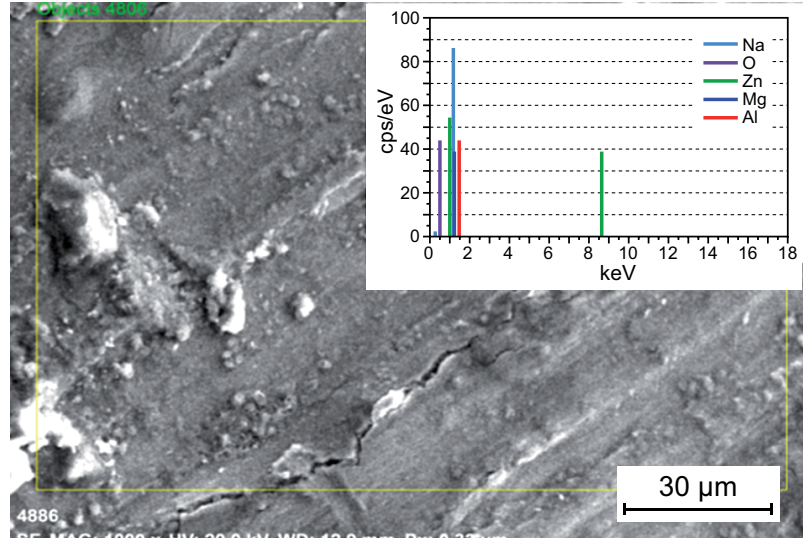

Fig. 8. Elemental composition of F01 specimen

DOI: 10.2478/kom-2020-0005

Koroze a ochrana materiálu 64(1) 29-37 (2020) 


\section{Immersion corrosion test}

The corrosion rate of the base material and the developed AZ31-NbC surface composite specimen with the immersion time is shown in Figure 9. The corrosion rate of the surface composite- $\mathrm{NbC}$ is higher when compared to the base material. The specimen B24 had a corrosion rate of $0.0124 \mathrm{~mm} /$ year, $\mathrm{B} 48$ had a corrosion rate

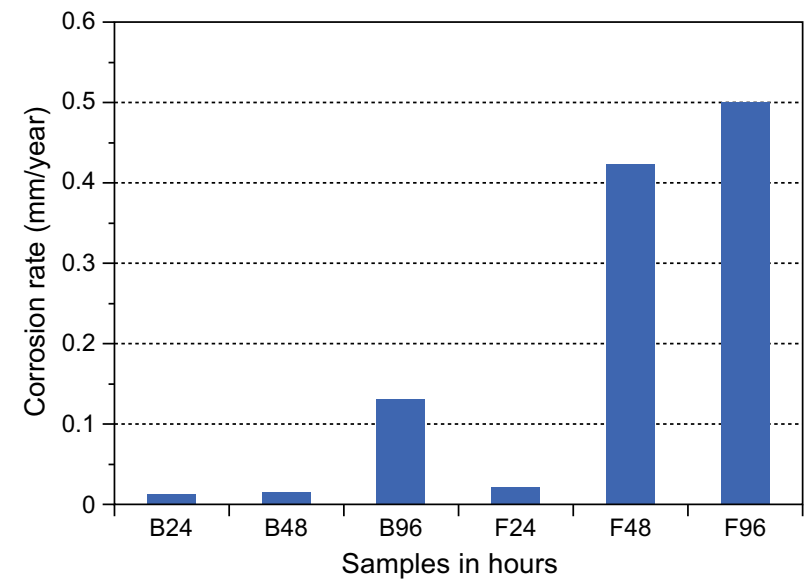

Fig. 9. Corrosion rate of the base material and developed surface composite

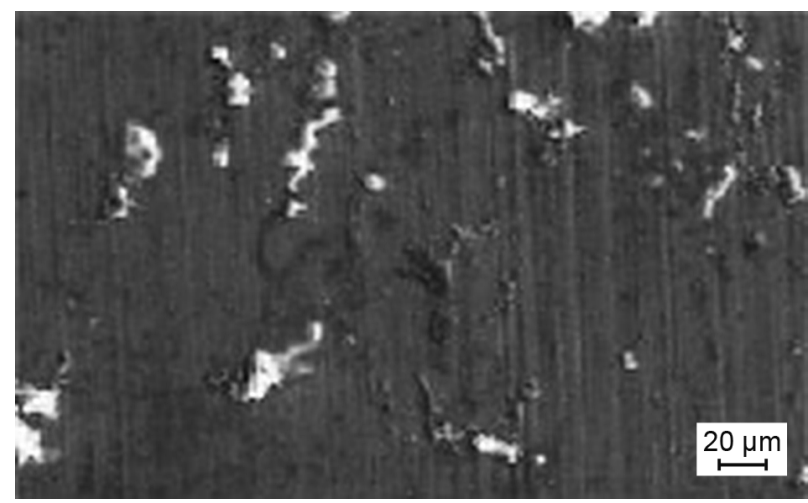

a)

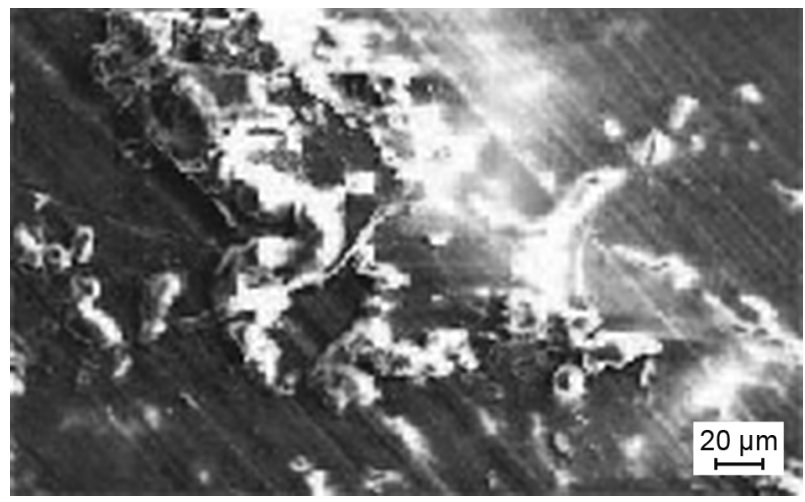

c) of $0.01414 \mathrm{~mm} /$ year, and B96 had a corrosion rate of $0.1316 \mathrm{~mm} /$ year. The developed surface composite had a corrosion rate of $0.0218 \mathrm{~mm} /$ year, $0.4231 \mathrm{~mm} /$ year and $0.5006 \mathrm{~mm} /$ year after 24 hours, 48 hours and 96 hours of immersion. The corrosion rate of the developed surface composite is 3.8 times higher than that of the base material after 96 hours of immersion in simulated sea water solution. The corrosion rate drastically increased for the developed surface composite. This is attributable to the presence of $\mathrm{Mg} / \mathrm{NbC}$ interfaces in the developed surface composite. The interfaces break the continuity of the magnesium matrix and hence create preferential sites for corrosion. Besides, the small radius of chloride ions favors preferential adsorption of chloride ions and formation of magnesium chloride. The higher solubility of magnesium chloride increases the new sites for corrosion and stimulates more dissolution of magnesium. Hence, the corrosion rate was fairly higher in the developed surface composite.

\section{Surface morphology}

Figure $10 \mathrm{a}$ and $10 \mathrm{~b}$ displays the surface morphology of developed surface composite AZ31-NbC alloy after 24 hours of corrosion test. Figure 10c and 10d shows the surface morphology of developed surface composite

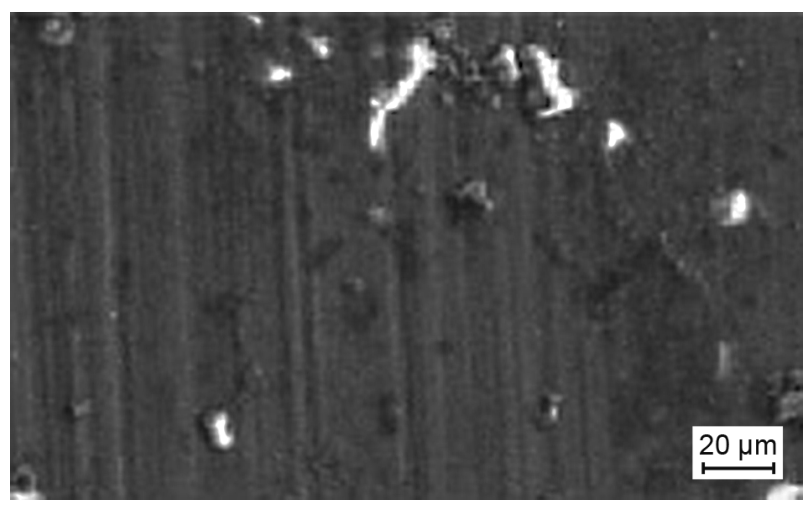

b)

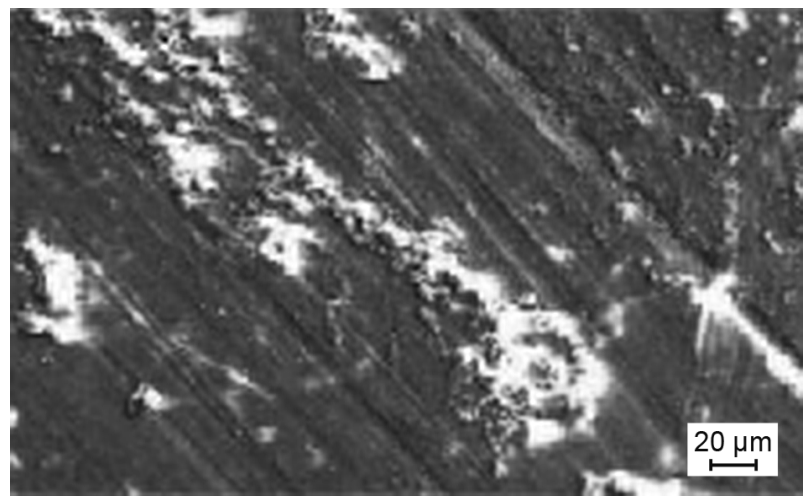

d)

Fig. 10. Corroded surface morphology of the base material and developed surface composite (continue on next page) 


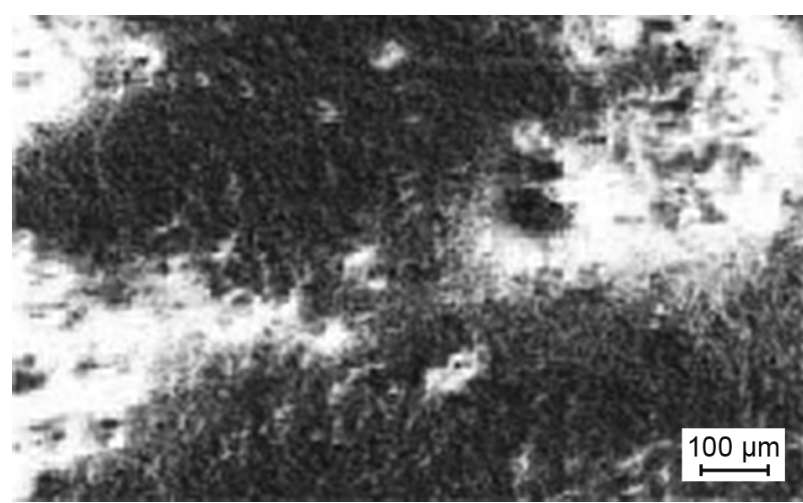

e)

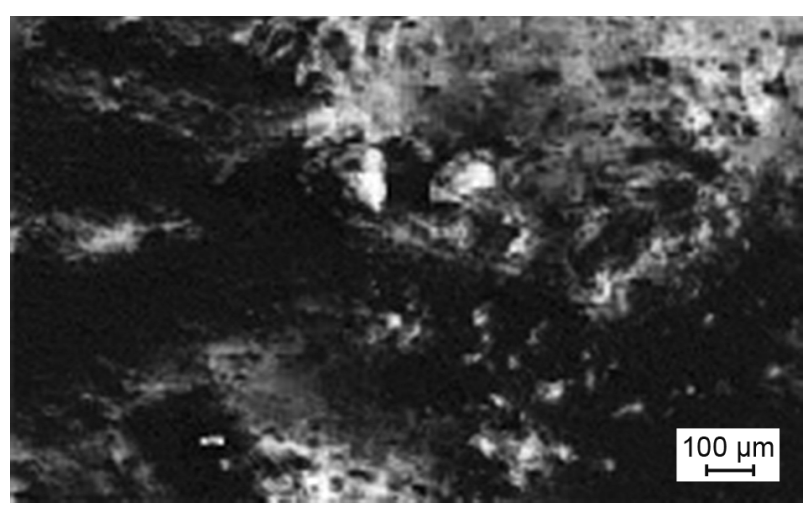

f)

Fig. 10. Corroded surface morphology of the base material and developed surface composite

AZ31-NbC alloy tested for 48 hours of corrosion test. Figure $10 \mathrm{e}$ and $10 \mathrm{f}$ indicates the surface morphology of base material after 96 hours of corrosion test. In the surface morphology of the corroded specimen, the white patches correspond to the corrosion products. The overall analysis reveals the absence of pitting phenomena in the corroded specimen.

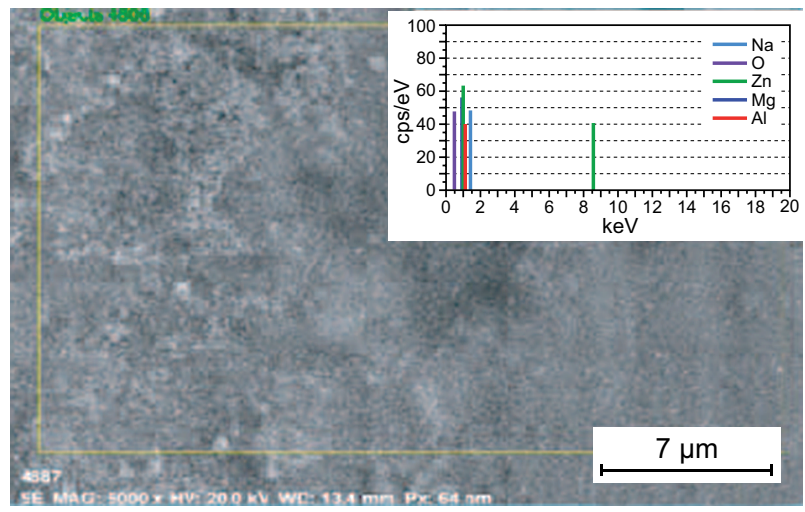

a) $24 \mathrm{~h}$

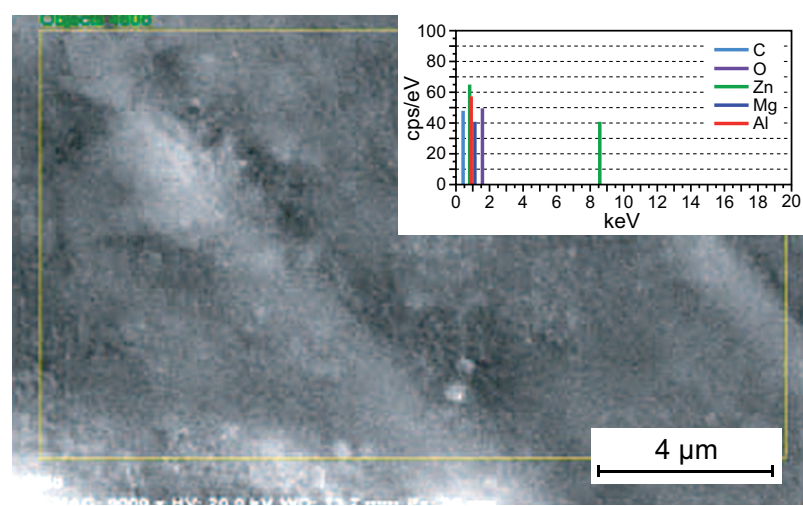

b) $48 \mathrm{~h}$

\section{Elemental composition analysis}

The elemental composition analysis reveals that the major elements in the corroded specimen are $\mathrm{Mg}, \mathrm{O}, \mathrm{Al}$, $\mathrm{Zn}$. Based on the EDS analysis the corrosion mechanism of the base material and the developed surface composite are as follows.

$$
\begin{gathered}
\mathrm{Mg} \rightarrow \mathrm{Mg}^{2+}+2 \mathrm{e}^{-} \\
2 \mathrm{H}_{2} \mathrm{O}+2 \mathrm{e}^{-} \rightarrow \mathrm{H} 2 \uparrow+2 \mathrm{OH}^{-} \\
\mathrm{Mg}^{2+}+2 \mathrm{OH}^{-} \rightarrow \mathrm{Mg}(\mathrm{OH})_{2} \\
\mathrm{Mg}^{2+}+2 \mathrm{Cl}^{-} \rightarrow \mathrm{MgCl}_{2}
\end{gathered}
$$

The interaction of specimen with the simulated sea water induces the formation of magnesium hydroxide as given by the equations (3) and (4). The tiny radius of $\mathrm{Cl}$ ions favours the adsorption of chloride ions on the surface of $\mathrm{Mg}(\mathrm{OH})_{2}$. It consequently favours the formation of $\mathrm{MgCl}_{2}$ as given by equation (7). The corrosion rate drastically increased for the developed surface composite AZ31-NbC after 24 hours of corrosion. This attributes to the presence of $\mathrm{Mg}$ matrix/ $\mathrm{NbC}$ that breaks the continuity of the $\mathrm{Mg}$ matrix and creating preferential

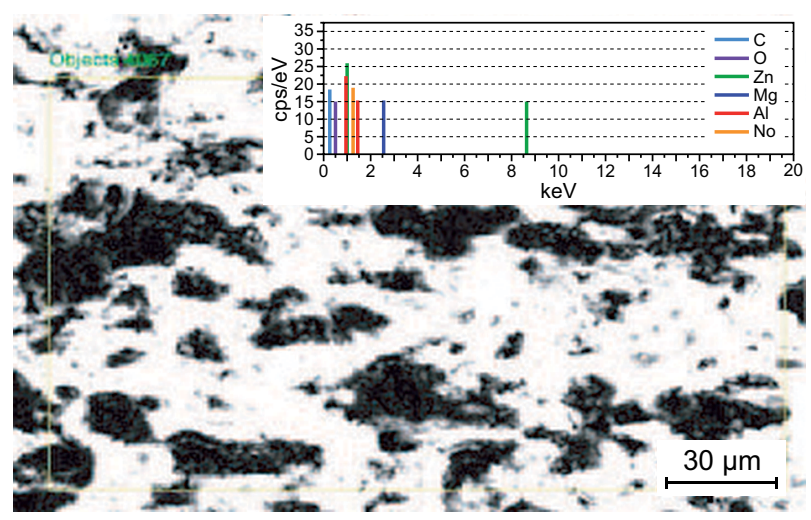

c) $96 \mathrm{~h}$

Fig. 11. Elemental composition analysis of developed surface composite AZ31-NbC: a) after 24 hours of corrosion; b) after 48 hours of corrosion; c) base material after 96 hours of corrosion 
regions for corrosion, which is similar to the observation of Chan Chiu et al. [20]. This increases the corrosion rate of the developed surface composite than that of the base material.

\section{CONCLUSION}

Friction stir processing was applied on AZ31 alloy with $\mathrm{NbC}$ reinforced to develop surface composite. The microhardness, corrosion, and tribological characteristics of the developed surface composites were investigated. The results demonstrated as follows:

- The microstructure shows the dispersed $\beta-\mathrm{Mg} 17 \mathrm{~A} 112$ ( $\beta$-phase), and fine grains in the developed surface composite, and the fine distribution of $\mathrm{NbC}$ were obtained.

- The microhardness of the base material is $56 \mathrm{Hv}$ and that of the develop surface composite is $69 \mathrm{Hv}$.

- The wear rate of the developed surface composite is lower than that of the base material at all the test loads.

- The immersion corrosion results indicated that the corrosion rate of the surface composite is higher than that of the base material.

\section{REFERENCES}

1. A. S. Handbook, Magnesium and magnesium alloys, ASM International 1999, pp. 106-118.

2. M. K. Kulekci: Magnesium and its alloys applications in automotive industry, The International Journal of Advanced Manufacturing Technology 2008, 39, 851-865.

3. V. V. Ramalingam, P. Ramasamy, M. D. Kovukkal, G. Myilsamy: Research and development in magnesium alloys for industrial and biomedical applications: a review, Metals and Materials International 2019, 1-22.

4. W. J. Joost, P. E. Krajewski: Towards magnesium alloys for high-volume automotive applications, Scripta Materialia 2017, 128, 107-112.

5. S. Mathaudhu, A. Luo, N. Neelameggham, E. Nyberg, W. Sillekens: Essential readings in magnesium technology, Springer: New York, 2016.

6. D. S. Kumar, C. T. Sasanka, K. Ravindra, K. Suman: Magnesium and its alloys in automotive applications - A review", Am. J. Mater. Sci. Technol. 2015, 4, 12-30.

7. S. T. Peters: Handbook of Composites, Springer Science and Business Media, 2013.

8. S. Suresh: Fundamentals of metal-matrix composites, Elsevier: Amsterdam, 2013.

9. P. S. Bains, S. S. Sidhu, H. Payal: Fabrication and machining of metal matrix composites: a review, Materials and Manufacturing Processes 2016, 31, 553-573.

10. M. Nováková, O. Chocholatý, A. Kř́ž: The influence of deformation on the corrosion properties of the material, Koroze a ochrana materialu 2017, 61, 86-90.

11. R. S. Mishra, Z. Ma, I. Charit: Friction stir processing: a novel technique for fabrication of surface composite, Materials Science and Engineering: A 2003, 341, 307-310.

12. Z. Ma: Friction stir processing technology: a review, Metallurgical and Materials Transactions A 2008, 39, 642-658.
13. R. S. Mishra, Z. Ma: Friction stir welding and processing, Materials Science and Engineering: $R$ : reports 2005, 50, 1-78.

14. R. S. Mishra, M. W. Mahoney, Y. Sato, Y. Hovanski, R. Verma: Friction stir welding and processing VI: John Wiley and Sons: Hoboken, 2011.

15. R. S. Mishra, P. S. De, N. Kumar: Friction stir welding and processing: science and engineering: Springer: New York, 2014.

16. J.-Y. Kim, J.-W. Hwang, H.-Y. Kim, S.-M. Lee, W.-S. Jung, J.-W. Byeon: Fabrication of AZ31/CNT surface nano-composite by double-pass friction stir processing, Archives of Metallurgy and Materials 2017, 62, 1039-1042.

17. Y. Morisada, H. Fujii, T. Nagaoka, M. Fukusumi: MWCNTs/ /AZ31 surface composites fabricated by friction stir processing, Materials Science and Engineering: A 2006, 419, 344-348.

18. M. Jamshidijam, A. Akbari-Fakhrabadi, S. M. Masoudpanah, G. H. Hasani, R. V. Mangalaraja: Wear behavior of multiwalled carbon nanotube/AZ31 composite obtained by friction stir processing, Tribology Transactions 2013, 56, 827-832.

19. A. A. Nia, S. Nourbakhsh: Microstructure and mechanical properties of AZ31/SiC and AZ31/CNT composites produced by friction stir processing, Transactions of the Indian Institute of Metals 2016, 69, 1435-1442.

20. C. Chiu, H.-C. Liu: Mechanical properties and corrosion behavior of WZ73 Mg Alloy/SiCp composite fabricated by stir casting method, Metals 2018, 8, 424.

21. C. Chang, Y. Wang, H. Pei, C. Lee, X. Du, J. Huang: Microstructure and mechanical properties of nano- $\mathrm{ZrO}_{2}$ and nano$\mathrm{SiO}_{2}$ particulate reinforced $\mathrm{AZ} 31-\mathrm{Mg}$ based composites fabricated by friction stir processing, Key Engineering Materials 2007, 114-119.

22. V. V. R, P. R, and G. M: Synthesis and Characterization of Magnesium Alloy Surface Composite $\left(\mathrm{AZ91D}-\mathrm{SiO}_{2}\right.$ ) by Friction Stir Processing for Bioimplants, Silicon 2019, 6, 18.

23. R. V. Vignesh, R. Padmanaban, M. Govindaraju, G. S. Priyadharshini: Mechanical properties and corrosion behaviour of AZ91D-HAP surface composites fabricated by friction stir processing, Materials Research Express 2019, 6, 085401 .

24. G. Faraji, P. Asadi: Characterization of AZ91/alumina nanocomposite produced by FSP, Materials Science and Engineering: A 2011, 528, 2431-2440.

25. D. Lu, Y. Jiang, R. Zhou: Wear performance of nano- $\mathrm{Al}_{2} \mathrm{O}_{3}$ particles and CNTs reinforced magnesium matrix composites by friction stir processing, Wear 2013, 305, 286-290.

26. V. Kondaiah, P. Pavanteja, P. A. Khan, S. A. Kumar, R. Dumpala, B. R. Sunil: Microstructure, hardness and wear behavior of AZ31 Mg alloy - fly ash composites produced by friction stir processing, Materials Today: Proceedings 2017, 4, 6671-6677.

27. M. Balakrishnan, I. Dinaharan, R. Palanivel, R. Sivaprakasam: Synthesize of AZ31/TiC magnesium matrix composites using friction stir processing, Journal of Magnesium and Alloys 2015, 3, 76-78.

28. M. Tang, Z. Feng, X. Wu, W. Wang, G. Li, Z. Yan, et al.: Microarc oxidation coatings containing $\mathrm{TiC}$ and $\mathrm{NbC}$ on magnesium alloy, Surface Engineering 2019, 1-9.

29. V. Sharma, U. Prakash, B. M. Kumar: Surface composites by friction stir processing: A review, Journal of Materials Processing Technology 2015, 224, 117-134. 